equal parts of sulphathiazole and boric acid powder. Hollender (1943) recommends sulphanilamide, provided it be mixed with boric acid powder, for if used alone it forms an obstructing cork. The choice between sulphanilamide and sulphathiazole depends on the bacteriological nature of the dischargesulphathiazole being used in the presence of a staphylococcic or pneumococcic infection, and sulphanilamide in the presence of a streptococcic infection.

The first and second treatments described have allowed many recruits to pass into the Forces.

Darlington. W. S. Thacker Neville, M.D.Dub., F:R.C.S.Ed. BiBLIOGRAIHY

Banham, T. M. (1944). J. Laryngol.-otol., 59, 119.

Carruthers, D. G. (1943). Diseases of the Ear, Nose and Throat, pp. 235, 387, Sydney.

Hollender, A. R. (1943). Office Treatment of Nose and Throat and Ear, p. 422, Chicago.

Lederman, M. D. (1917). Laryngoscope, 27, 800.

Levine, M. (1938). Practical Orology, 2nd ed., Philadelphia.

\section{A Case of Gunshot Wound of the Abdomen}

The case described below is remarkable for the length of bowel. resected at operation, and also raises the question of the dosage of morphine that should be used for the severely injured.

\section{CASE Notes}

An Indian sepoy aged 24 was brought to a mobile surgical unit 18 hours after he had received a rifle-shot in the abdomen. On examination he was found to have a ragged wound in the right iliac fossa through which a large mass of intestines was protruding. This had been covered with a shell dressing. He was accompanied by a medical officer, who said that when brought to him some two or three hours previously the patient was so distressed that it was decided to give him a large dose of morphine. As it was impossible to have a light at the time, the medical officer was uncertain how much morphine he was giving, but he believed it was from $1 / 2$ to 1 gr. No attempt had been made to resuscitate the man with plasma. His condition when seen by us was very poor. His breathing was slow and shallow and his pulse rapid and feeble. He was fairly alert mentally, and did not appear to be very uncomfortable. He was given atropine $1 / 50 \mathrm{gr}$. hypodermically and was taken to the theatre for operation without delay. Anaesthesia was induced with ethyl chloride, followed by ether on an open mask (Ogston's). Carbon dioxide had to be used for adequate breathing, and nikethamide (coramine) was injected hypodermically and intravenously (1.7 c.cm. each). An intratracheal tube was passed under direct vision and oxygen was given throughout.

The wound was enlarged and practically the whole of the ileum was found to be prolapsed. It was also perforated in a number of places and was gangrenous. Twelve and a half feet of the small intestine from the ileo-caecal valve upwards was rapidly resected, and the proximal end was inserted into the transverse colon, the distal end being invaginated into the caecum. Sulphanilamide powder was introduced into the peritoneum and the wound was closed, with a drain into the recto-vesical pouch. During the operation one pint of plasma was given by drip.

Convalescence was complicated only by sepsis in the wound. The general condition of the patient was remarkably good throughout, and he spent the first few days wondering why he was not getting his bowels open and why he was denied his rice and vegetables. A continuous intravenous drip saline was maintained for four days with sulphapyridine in each bottle, and an unsuccessful attempt was made to keep a Ryle tube in place. The patient was evacuated in very good condition on the seventeenth day.

\section{COMMENTARY}

This case brings out a point which has been learned by experience-namely, that in abdominal wounds more than six hours old it is undesirable to postpone operation for the sake of resuscitative measures however grave the patient's condition may be. In this case plasma was given as early as possible, but the operation was not delayed in the hope of an improvement in the general condition.

Although a large dose of morphine is by no means ideal in such cases from the anaesthetist's point of view, it might well be argued that this patient would not have survived to reach the surgical team had not a large dose of morphine been given. In view of the variety of ways in which individuals react to morphine it is not suggested that the use of a massive dose, as in this case, should be indulged in as a routine, but it is perhaps reasonable to speculate that this was one of those fortunate people who apparently react wholly favourably to morphine, and that it enabled him to survive this extremely severe injury and operation.

R. K. A. van Someren, F.R.C.S.Ed., Major, R.A.M.C. Surgical Specialist to a Mobile Surgical Unit.

J. D. Laycock, M.B., B.S., D.A.,

Major, R.A.M.C. ;
Anaesthetic Specialist to a Mobile Surgical Unit.

\section{Reviews}

\section{YEARBOOK OF UROLOGY}

The 1944 Year Book of Urology. By Oswald S. Lowsley, M.D., F.A.C.S. London: H. K. Lewis and Co.

Although urological research has been severely restricted by the war, the 1944 Year Book of Urology does not appear to have suffered. It is as full of interesting material as its predecessors. Perhaps the only reminders in its pages that the world is at war are the absence of any reports or papers from clinics in occupied Europe, and the appearance of a special article on the use of penicillin in the treatment of urogenital infections. This article, by Capt. L. R. Reynolds and Lieut.-Cmćr. Weyrauch, is based on observations made on a very large series of cases examined in various hospitals of the U.S. Navy. It is particularly worthy of attention. There can be no doubt that penicillin is of inestimable value in the treatment of gonorrhoea, especially in those complicated cases in which the sulphonamides have proved successful. A course of 100,000 units of penicillin will bring about a cure in well over $95 \%$ of all patients with uncomplicated gonococcal urethritis if the drug is given in ten doses of 10,000 units every three hours. In the treatment of non-gonococcal infections the effect of penicillin is unfortunately much less impressive.

The Year Book also contains interesting articles on the surgery of the kidney and the adrenals. Dr. S. F. Wilhelm of New York has planned a new technique for operations on cases of obstruction at the pelvi-ureteric junction. Instead of implanting the divided ureter into the pelvis he splits the end of the ureter and implants the pelvis into it, thus avoiding the possibility of forming an obstructive flap. Drs. E. S. Judd and F. Z. Havens of the Mayo Clinic contribute a useful article on the treatment of the traumatic avulsion of the skin of the penis and the scrotum. They describe the use of both grafts and plastic operations. Dr. L. E. Sutton of Syracuse University gives an account of a case treated by first carrying out a perineal urethrotomy and then burying the denuded penis under the skin of the abdominal wall. All these articles are beautifully illustrated, and the 1944 Year Book of Urology maintains the high standard of its predecessors.

\section{PHYSICAL MEDICINE}

Physical Medicine in General Practice. By William Bierman, M.D. (Pp 654 ; illustrated. 37s.) New York: Paul B. Hoeber, Inc.; London:

Before reviewing any book it is customary for the reviewer to read the preface with some care, so that the intentions of the author and the scope of the work may be gathered. On this occasion it was decided to go through the book and then, as it were, write a preface for it, as found by personal study. On doing so, three outstanding impressions were left: first, that here was a book that gave an accurate, comprehensive, and yet fairly judicial conspectus of the possibilities of physical medicine for general practitioners who wished to be well informed on the subject; secondly, there jumped to the mind the old Chinese proverb that "A picture is worth a thousand words," because the numerous line illustrations throughout the book seemed to clarify some point of technique or help the practitioner to visualize some special position of patient or apparatus; and, thirdly, that those techniques which need considerable "filling out" have suitable references at the end of each chapter. It was interesting to find, on reading the preface, that all these three points were particularly emphasized by the author.

Though the book keeps closely to its original aim of being informative for general practitioners, there are here and there useful practical hints on technique that can with advantage be absorbed by the physical medicine specialist or the physiotherapist. Considering the size of the volume there are extremely few techniques or statements that are not consistent with the best British practice in this field. The technique illustrated on page 156 (Fig. 91) is not one that would be considered free from risk of burn in England, while that in Fig. 92 would be considered a safe and useful method. It is also rather 